\title{
Influência da Adição de Cal Hidratada na Aderência do Preparo da Base Chapisco e Argamassa para Revestimento
}

\author{
Influence of the Addition of Hydrated Lime on \\ the Adhesion of the Preparation of the Roughcast \\ Base and Mortar for Coating
}

\author{
André Miranda dos Santos ${ }^{1}$, Ângelo Just Costa e Silva ${ }^{2}$, \\ João Manoel de Freitas Mota ${ }^{3}$
}

\footnotetext{
${ }^{1}$ Mestre, Instituto Federal de Pernambuco-IFPE, Departamento de Infra-estrutura e Construção (DAIC), Av. Prof. Luís Freire, 500 - Cidade Universitária, CEP: 50740-545, Recife, Pernambuco, Brasil

${ }^{2}$ Professor Doutor, Universidade Católica de Pernambuco, UNICAP, ICAM-TECH - Departamento de Engenharia Civil, Rua do Príncipe, 526, Boa Vista, CEP: 50050-900, Recife, Pernambuco, Brasil

${ }^{3}$ Professor Doutor, Instituto Federal de Pernambuco-IFPE, Departamento de Infra-estrutrua e Construção (DAIC), Av. Prof. Luís Freire, 500, Cidade Universitária, CEP: 50740-545, Recife, Pernambuco, Brasil

E-mail: andresantos@recife.ifpe.edu.br, angelo@tecomat.com.br, joaomota@recife.ifpe.edu.br
}

\section{RESUMO}

Considerando as tecnologias relacionadas aos revestimentos de paredes nas edificações, releva-se a importância de preparo da base chapisco. Entretanto, não se pode desconsiderar a importância das demais camadas do sistema de revestimentos de argamassas na resistência de aderência à tração, com maior ênfase nos casos das fachadas. A aderência relaciona-se basicamente à técnica executiva empregada e aos materiais utilizados, destacando o teor de cimento e água adicionada no traço, tendo em vista que a penetração da água coloidal nos poros da base, propicia a microancoragem (travamento mecânico de cristais de sulfoaluminato de cálcio hidratado ou etringita e silicato de cálcio hidratado, conforme princípio dos poros ativos) que governa à aderência. Podem-se destacar alguns benefícios do chapisco na aderência dos revestimentos: (i) resistência ao cisalhamento, função da rugosidade (macroancoragem); (ii) uniformização da absorção; (iii) parte da barreira física do sistema de revestimento da fachada. Essa pesquisa objetivou verificar a influência da adição de cal em relação a massa de cimento, no chapisco e no sistema chapisco mais reboco, nos teores $(0 \%, 5 \%, 10 \%$ e $15 \%$ ) em paredes com blocos cerâmicos e de concreto. Os resultados obtidos indicaram a importante contribuição da adição de cal como incremento da resistência de aderência à tração de revestimentos argamassa$\operatorname{dos}[1]$.

Palavras-chave: Aderência. Argamassa. Cal hidratada.

\section{ABSTRACT}

Considering the technologies related to wall coverings in buildings, the importance of preparing the base roughcast is important. However, the importance of the other layers of the mortar coating system cannot be disregarded in the tensile strength, with more emphasis on the cases on the facades. Adherence is basically related to the executive technique employed and the materials, highlighting the cement and water content added in the trace, considering that the penetration of colloidal water in the pores of the base, providing microancorating (mechanical locking of sulfo-aluminate crystals of hydrated calcium or ethringtite and hydrated calcium silicate, according to the principle of the pores active) and governs in bond. It can be highlighted some benefits of roughcast on the adhesion of coatings: (i) shear resistence of the, function of Roughness (macroarmage); (ii) uniformity of coating absorption; (iii) part of the physical barrier of the façade cladding system. This research aimed to verify the influence of pure lime addition in relation to cement mass, roughcast and roughcast more plaster system, on the contents $(0 \%, 5 \%, 10 \%$ and $15 \%)$ on walls with ceramic and concrete blocks. The results indicated the importance of adding lime as an increase in tensile bond strength of mortar coatings [1].

Keywords: Adherence; mortar; hydrated lime. 


\section{INTRODUÇÃO}

Uma etapa primordial para um satisfatório desempenho dos sistemas de revestimento de argamassa é o preparo da base, onde diversas pesquisas buscam desenvolver critérios técnicos objetivando garantir que a propriedade de resistência de aderência à tração atenda a normas pertinentes [2, 3].

O preparo da base propicia melhor ancoragem mecânica do revestimento de argamassa, seja pelo método tradicional (aplicação de chapisco) ou pelo transporte do cálcio (espécie de princípio ativo) para os poros da base através da pulverização de solução de cal, ou ainda pelo simples umedecimento do substrato. Todos os casos devem atender os níveis de resistência de aderência normalizados [4].

A relação água/aglomerante e ar aprisionado são fatores relevantes no desempenho da aderência do chapisco, uma vez que ambos os casos controlados ocorrerá redução da porosidade na interface [5]. Ademais, esta relação deve ser vista também como um requisito de controle tecnológico da argamassa e de todos os materiais cuja matriz seja cimentícia, na medida em que quanto maior o coeficiente de sorptividade (função da porosidade), maior será a percolação e a possibilidade de difusão de agentes deletérios, mitigando, por conseguinte, a durabilidade [6].

Sabe-se que nos revestimentos de argamassa, a aderência aos substratos depende de fatores físicos, químicos, mecânicos, operação da aplicação, condições ambientais, dentre outros [7]. Portanto, a Figura 1 apresenta condicionantes que influenciam na aderência das argamassas.

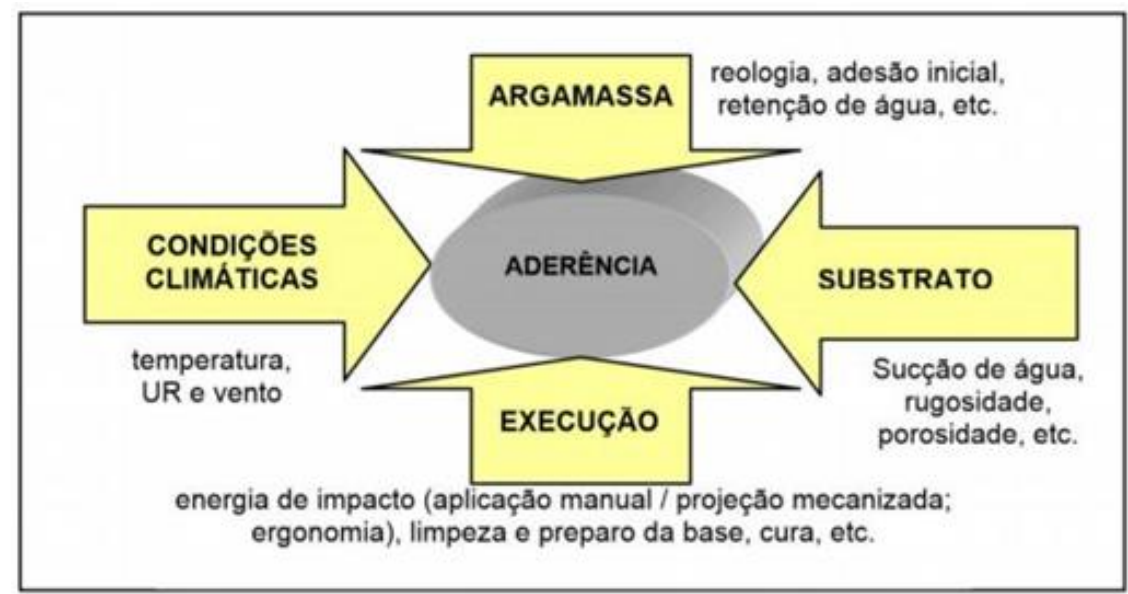

Figura 1: Fatores importantes na aderência das argamassas [8].

O sistema de revestimento de argamassa, mais precisamente a camada de preparo da base (chapisco) e a camada de revestimento (reboco ou emboço) aderido ao substrato, tem adesão inicial influenciada pelas propriedades reológicas argamassa, devido a tensão superficial da superfície do substrato no momento do contato, onde resultará nas forças de adesão que devem ser fortes e estáveis [9, 10].

Avaliando a aderência do chapisco à base, verifica-se um processo predominantemente mecânico, em decorrência da transferência da água no estado coloidal (grão de cimento hidratado) para o substrato. A sucção inicial da base possibilita a entrada de parte da pasta cimentícia nos poros da alvenaria no estágio de dissipação de hidróxidos, silicatos e aluminatos, promovendo a ancoragem mecânica por travamento após aperto dos cristais surgidos mais abundantemente no estado de precipitação até o endurecimento [11].

Outro aspecto que impacta na aderência é a porosidade do substrato [12], onde substratos de alta absorção provoca insuficiência de água para a completa hidratação do cimento próximo a área de interface entre o substrato e a argamassa de preparo (chapisco), o que torna essa região com fragilidade (aproximadamente 20 micrômetros). Por outro lado, em um substrato com baixa absorção, observa-se um acúmulo de água na zona da interface, fazendo com que surja uma maior porosidade (devido efeito parede que conduz a elevada relação água/cimento nessa zona) e, consequentemente, uma condição desfavorável [13, 14]. As Figuras 2 e 3 apresenta o mecanismo de aderência das argamassas em blocos cerâmicos [15]. 


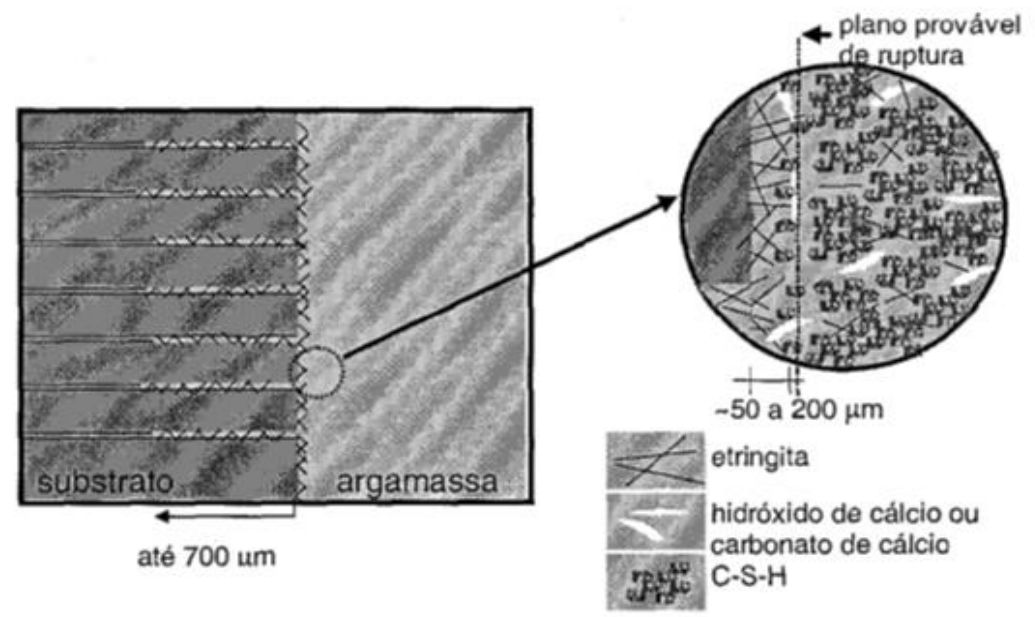

Figura 2: Representação esquemática do mecanismo de aderência entre argamassas de cimento e cal e os blocos cerâmi$\cos [15]$.

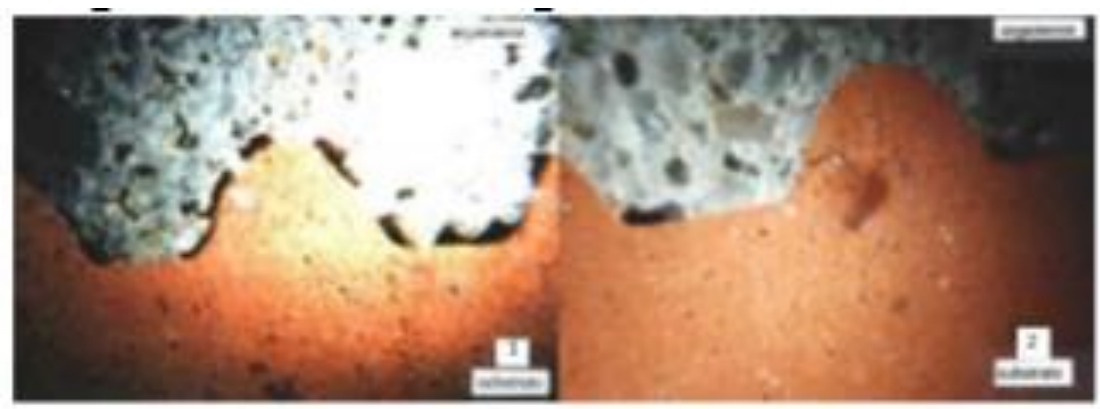

(a)

(b)

Figura 3: Interface argamassa bloco cerâmico [11].

A Figura 3 mostra fotografias obtidas em lupa estereoscópica, onde (a): refere-se à argamassa com traço 1:3 (cimento e areia) e (b): 1:1/4:3 (cimento, cal e areia). Observa-se em (a) uma quantidade de vazios elevado na interface (regiões mais escuras), enquanto em (b) a adição de cal proporciona teor de vazios reduzido, caracterizado pela maior extensão de aderência.

Justifica-se a diferença de porosidade, devido às argamassas mistas de cimento e cal ter, fundamentalmente, maior trabalhabilidade no estado fresco e maior extensão de aderência no estado endurecido. Observa-se que, na interface na Figura 3 (b) a estrutura é mais densa e contínua, bem como apresenta diminuição de microfissuras.

Não se pode deixar de destacar a importância reológica da argamassa mista de cimento e cal, pois identificou-se ser mais determinante do que o universo rugoso do substrato, considerando a aderência de resistência à tração $[16,17]$. Todavia, foi verificado que no caso dos tijolos cerâmicos a porosidade deriva da temperatura de sinterização, onde a aderência dos revestimentos de argamassa pode ser incrementada em até $50 \%$ quando o cozimento ficar entre $750^{\circ} \mathrm{C}$ e $950^{\circ} \mathrm{C}$ [18].

O sistema de poros em substrato cerâmico apresenta-se com raios aproximadamente constantes ao longo do tempo. Já a argamassa no estado fresco apresenta um sistema de poros de raios variáveis com o tempo, entretanto esses raios decrescem com a hidratação dos aglomerantes da argamassa. Quando a argamassa é lançada no substrato poroso de capilares inicialmente vazios, observa-se que os raios médios da argamassa são superiores aos dos capilares do substrato, propiciando o fluxo da água no sentido da argamassa para o substrato [19]. Neste fenômeno de sucção, ocorre um aperto mecânico das partículas sólidas da argamassa, tendo em vista a depressão dos capilares, concomitantemente com uma aceleração da cristalização decorrentes da hidratação dos produtos dissolvidos do aglomerante, resultando na ancoragem [20].

Os poros da argamassa variam de diâmetro $0,001 \mu \mathrm{m}$ à aproximadamente $5 \mu \mathrm{m}$, por conseguinte, os poros do substrato que ultrapassarem o valor máximo de $5 \mu \mathrm{m}$ serão considerados poros inoperantes, não ati- 
vos por não possuírem força capilar necessária. O raio médio dos poros das argamassas pode ser aumentado para proporcionar maior capacidade de sucção da base, alterando as proporções dos aglomerantes e agregado, mais especificamente elevando o módulo de finura do agregado miúdo [21].

Portanto, a resistência de aderência à tração das argamassas, ocorre por conta da microancoragem devido a ligação entre substrato e a argamassa pelos cristais de etringita e C-S-H, bem como pela macroancoragem imposta pela rugosidade do substrato que influencia no cisalhamento [22]. A Figura 4 mostra cristais de etringita no interior de um poro.

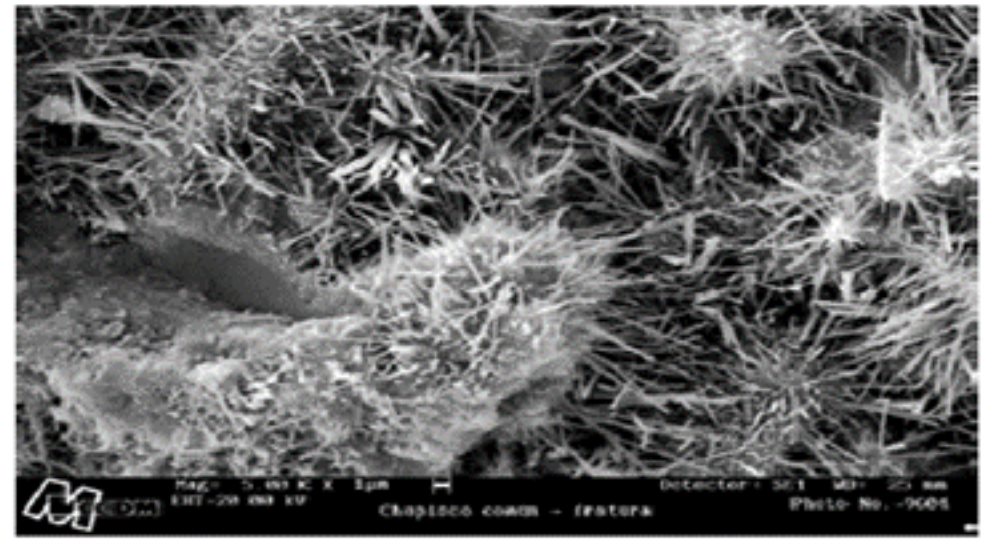

Figura 4: Cristais de etringita na interface do chapisco comum/substrato.

Contudo, embora a aderência seja necessária em todas as camadas do sistema de revestimento de argamassa, o chapisco também contribui: com a ancoragem da camada posterior; regula a porosidade e uniformiza a absorção; engloba o sistema de revestimento, contribuindo com a exigência normativa acerca da barreira física, enquanto fachada [23-26].

Ademais, altas temperaturas afetam o desempenho de chapisco. Moura [27] estudou a cura em revestimentos de argamassa, onde em todas as combinações (três tipos de argamassa com chapisco e revestimento), concluiu que o efeito do calor resultou na queda de resistência de aderência das amostras.

No que se refere a solução de cal, foi observado a partir de análises petrográficas e cristalográficas, que na interface entre argamassa e blocos cerâmicos se encontra uma camada de cálcio denominada de "camada de aderência" (microancoragem com predominância de etringita) [28]. Também verificou-se que o povoamento de cálcio em base cerâmica forma uma estrutura cristalina mais densa nas interfaces das argamassas com os substratos cerâmicos, justificando assim, uma maior resistência de aderência mecânica [29].

Pesquisas mostraram o efeito benéfico da solução de cal sobre alvenarias de blocos cerâmicos e de concreto na aderência de revestimentos de argamassas [30- 32].

Estudo semelhante concluiu que o revestimento aplicado sobre solução de cal apresentou resistência de aderência à tração superior ao aplicado sobre chapisco [33]. Todavia, trabalhos científicos mostraram que a relação água/cimento é inversamente proporcional à resistência de aderência à tração [6, 14, 34]. Entretanto, adições minerais elevam esta propriedade e promove uma importante forma de ruptura, no bloco [35].

Esse trabalho teve como objetivo verificar a influência da cal na resistência de aderência à tração, exclusivamente do chapisco em base cerâmica, e, na aderência de todo sistema de revestimento de argamassa (chapisco mais camada de reboco) em paredes com blocos cerâmico e concreto, sendo adicionados os teores de $5 \%, 10 \%$ e $15 \%$ de cal. Esta verificação da aderência de todo o sistema de revestimento, conduz a uma contribuição importante na literatura.

\section{MATERIAIS E MÉTODOS}

Os ensaios realizados objetivaram identificar especificamente a influência da adição de cal nas condições, a saber: (1) resistência de aderência à tração somente do "chapisco" (interface direta) na parede com blocos cerâmicos; (2) resistência de aderência à tração do sistema de revestimento "chapisco mais o reboco industrializado" nas paredes com blocos cerâmicos e concreto.

Utilizou-se argamassa industrializada para melhor padronizar as propriedades desse material, mitigando uma componente de variabilidade. Todos os materiais foram homogeneizados em betoneira. Serão mostrados arranjos experimentais e resultados dessas duas situações distintamente. 


\subsection{Materiais Utilizados}

A Tabela 1 mostra os tipos de materiais utilizados na pesquisa.

Tabela 1: Elementos e tipos de materiais.

\begin{tabular}{c|c|c}
\hline ARGAMASSAS UTILIZADAS & MATERIAIS & OBSERVAÇÃO \\
\hline Argamassa de assentamento para elevação das paredes & Cimento, cal, areia e água & \\
\hline Chapisco & Cimento, areia e água (*cal) & *adição de cal \\
\hline Revestimento de argamassa & Argamassa industrial e água, $(*$ cal) & *adição de cal \\
\hline
\end{tabular}

A argamassa industrializada para o revestimento é amplamente utilizada na Região Metropolitana do Recife (RMR). As características do cimento Portland CP II Z-32 são apresentadas na Tabela 2.

Foi adicionada aos chapiscos, em algumas famílias, cal cálcica do tipo CH-I conforme propriedades discorrida na Tabela 3 .

Tabela 2: Características do cimento.

\begin{tabular}{|c|c|c|c|}
\hline \multicolumn{3}{|c|}{ DETERMINAÇÃO (CP II Z-32) } & RESULTADOS \\
\hline \multirow{3}{*}{$\begin{array}{l}\text { Caracterização } \\
\text { Física }\end{array}$} & \multicolumn{2}{|c|}{ Densidade Aparente $\left(\mathrm{g} / \mathrm{cm}^{3}\right)$} & 1,2 \\
\hline & \multicolumn{2}{|c|}{ Massa Específica $\left(\mathrm{g} / \mathrm{cm}^{3}\right)$} & 3,09 \\
\hline & $\begin{array}{l}\text { Resistência à } \\
\text { Compressão }\end{array}$ & 28 dias $(\mathrm{MPa})$ & 39,5 \\
\hline \multirow{6}{*}{$\begin{array}{c}\text { Caracterização } \\
\text { Química (\%) }\end{array}$} & \multirow{4}{*}{$\begin{array}{l}\text { Composição } \\
\text { potencial do } \\
\text { Clínquer }\end{array}$} & $\mathrm{C}_{3} \mathrm{~S}$ & $20-70$ \\
\hline & & $\mathrm{C}_{2} \mathrm{~S}$ & $10-60$ \\
\hline & & $\mathrm{C}_{3} \mathrm{~A}$ & $1-15$ \\
\hline & & $\mathrm{C}_{4} \mathrm{AF}$ & $5-15$ \\
\hline & \multicolumn{2}{|r|}{$\mathrm{CaO}$} & $0-2$ \\
\hline & \multicolumn{2}{|r|}{$\mathrm{MgO} / \mathrm{SO}_{3}$} & $0-6$ \\
\hline
\end{tabular}

Fonte: Fabricante

Tabela 3: Características da cal hidrata.

\begin{tabular}{c|c}
\hline DESCRIÇÃo & RESULTADOS \\
\hline Mineral & Calcário \\
\hline Anidrido Carbônico $-\mathrm{CO}_{2}$ & $\leq 2,21$ \\
\hline $\mathrm{Ca}(\mathrm{OH})_{2}$ & $\geq 92,5 \%$ \\
\hline Anidrido Sulfúrico $-\mathrm{SO}_{3}$ & $\leq 0,05$ \\
\hline $\mathrm{Mg}(\mathrm{OH})$ & $\leq 5,0 \%$ \\
\hline $\mathrm{SiO}_{2}$ & $\leq 1,3 \%$ \\
\hline Umidade & $\leq 2,0 \%$ \\
\hline Densidade Aparente & $0,56 \mathrm{~g} / \mathrm{cm}^{3}$ \\
\hline
\end{tabular}

Fonte: Fabricante

Foi utilizado o agregado miúdo areia natural de natureza quartzosa, amplamente usado na RMR (Tabela 4). 
Tabela 4: Características do agregado miúdo.

\begin{tabular}{c|c}
\hline DESCRIÇÃo & RESULTADOS \\
\hline Massa unitária & $1,3 \mathrm{~g} / \mathrm{cm}^{3}$ \\
\hline Módulo de finura & 2,28 \\
\hline Diâmetro máximo & $2,36 \mathrm{~mm}$ \\
\hline Teor de material pulverulento $(\%)$ & 2,38 \\
\hline
\end{tabular}

Foram erguidas paredes com blocos de vedação cerâmicos e de concreto para o ensaio de resistência de aderência à tração (Tabela 5).

Tabela 5: Características dos blocos.

\begin{tabular}{c|c|c|c|c}
\hline BASE & $\begin{array}{c}\text { DIMENSÕES } \\
\text { (L X C X A) } \\
\mathbf{c m}\end{array}$ & $\begin{array}{c}\text { ABSORÇÃO } \\
\text { TOTAL } \\
\mathbf{( \% )}\end{array}$ & $\begin{array}{c}\text { RESISTÊNCIA À COM- } \\
\text { PRESSÃO MÉDIA (MPa) }\end{array}$ & $\begin{array}{c}\text { IRA - INITIAL RATE } \\
\text { OF ABSORPTION } \\
\text { (g/200cm } / \mathbf{m i n})\end{array}$ \\
\hline $\begin{array}{c}\text { Bloco } \\
\text { Cerâmico }\end{array}$ & $9 \times 19 \times 19$ & 13,6 & 2,3 & 11,1 \\
\hline $\begin{array}{c}\text { Bloco de } \\
\text { Concreto }\end{array}$ & $9 \times 19 \times 39$ & 8,4 & 3,6 & 16,9 \\
\hline
\end{tabular}

A Tabela 6 mostra características referentes ao chapisco de referência (sem adição de cal) utilizado no preparo do substrato.

Tabela 6: Características do chapisco

\begin{tabular}{c|c|c}
\hline PROPRIEDADES & MÉTODO (NBR) & CHAPISCO 1:3 (VOLUME) \\
\hline Traço em massa & 13749 & $1: 3,23$ \\
\hline Relação água/cimento & - & 0,80 \\
\hline Água/materiais secos & - & 0,19 \\
\hline Aglomerante/agregado & - & 0,31 \\
\hline Consistência - Média (mm) & 13276 & 348 \\
\hline Módulo de Elasticidade - Média - (GPa) & 8802 & 10,79 \\
\hline
\end{tabular}

A água utilizada foi proveniente da rede de abastecimento pública da cidade do Recife, onde se verificou o pH da água próximo de 6,5.

\subsection{Arranjo Experimental}

Foram realizados ensaios de resistência de aderência à tração com somente, buscando verificar Famílias, com e sem adição de cal, nos teores: $0 \%, 5 \%, 10 \%$ e $15 \%$ (em relação a massa de cimento).

As duas condições estratégicas da aderência analisadas foram:

(i) Aderência exclusiva do "chapisco" $\rightarrow$ em alvenaria de bloco cerâmico (interface direta);

(ii) aderência de todo sistema de revestimento "chapisco mais o reboco industrializado" $\rightarrow$ em alvenarias de blocos cerâmicos e de concretos.

A condição (i) é justificado por se tratar da contribuição tecnológica para aderência simples na interface da argamassa de preparo da base (chapisco) à parede com bloco cerâmico, uma vez que este tipo de alvenaria predomina nas construções da RMR. A condição (ii) justifica-se pela importância de se verificar o desempenho da aderência de todo "sistema de revestimento completo". Portanto, essa concomitância representa uma contribuição à literatura, especificamente ao tema de aderência de argamassas inorgânicas.

O planejamento do arranjo experimental, contemplou a confecção de três painéis de alvenaria de vedação $(220 x 180) \mathrm{cm}$, sendo uma parede externa com bloco cerâmico (para aderência do chapisco puro) e as 
outras duas (uma com bloco cerâmico e outra com bloco de concreto) no interior do laboratório (para aderência do sistema chapisco mais revestimento de argamassa).

$\mathrm{O}$ traço para argamassa de assentamento das alvenarias (espessura de $10 \mathrm{~mm}$ ) foi em volume 1:1:6:1,5 (cimento, cal, areia e relação água/cimento).

A quantidade de água de amassamento adveio da mínima necessária para uma trabalhabilidade satisfatória na aplicação das argamassas de revestimento $(220 \pm 20 \mathrm{~mm}$ na mesa de flow table $)$. Em todos os casos, a preparação da base (chapisco) ocorreu 24 horas após a construção das paredes.

\subsubsection{Ensaio da resistência de aderência à tração exclusivo do "chapisco aplicado em alvenaria de bloco cerâmico (interface direta)".}

O traço do chapisco em volume foi 1:3:0,8 (cimento, areia, relação água/cimento), onde as Famílias estão representadas na Tabela 7.

Foram realizados ensaios para determinação da aderência com 12 exemplares por Família, sendo a idade 6 (seis) meses após aplicação, por profissional específico seguindo os procedimentos normativo [1].

Tabela 7: Famílias dos chapiscos utilizados

\begin{tabular}{c|l|c}
\hline \multicolumn{1}{|c|}{ FAMÍLIAS } & \multirow{1}{c}{ TRAÇO } \\
\hline SIGLA & \multicolumn{1}{|c}{ DESCÇÃO } & $1: 3: 0,8$ \\
\hline F1 & 0\% da cal (referência) & $1: 0,05: 3: 0,8$ \\
\hline F2 & $5 \%$ da cal (adição pura em relação a massa de cimento) & $1: 0,1: 3: 0,8$ \\
\hline F3 & 10\% da cal (adição pura em relação a massa de cimento) & $1: 0,15: 3: 0,8$ \\
\hline F4 & $15 \%$ da cal (adição pura em relação a massa de cimento) & \\
\hline
\end{tabular}

O prolongado tempo para realização do ensaio de aderência, propiciou verificar deixar a exposição da parede análoga às fachadas, posto que o painel, nesse caso, ficou em ambiente externo ao laboratório (figura $5)$.

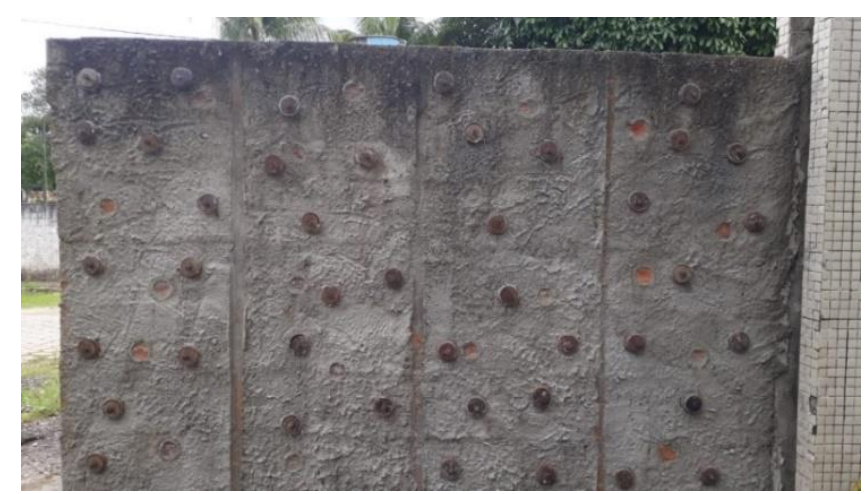

Figura 5: Parede de alvenaria de blocos cerâmicos com as Famílias de chapisco com alguns corpos de provas.

Os ensaios de arrancamento foram efetuados exclusivamente sobre a superfície do bloco, evitando as juntas da alvenaria, bem como aproximação entre os pontos. Assim, evitou-se interferência e possíveis fragilidades em regiões devido a cortes com broca especifica (serra copo). Foram executados corpos de prova circulares com $50 \mathrm{~mm}$ de diâmetro, sendo o aderímetro instalado sobre pastilhas metálicas coladas com adesivo epóxi de alta aderência (Figura 6). Para garantir uma superfície lisa e regular para colagem da pastilha metálica sobre o chapisco, foi instalado um aparato com comprimento de aproximadamente 1,5 $\mathrm{cm}$ de tubo em PVC com $50 \mathrm{~mm}$ de diâmetro fixado com silicone, de tal forma que após 24 horas fosse preenchido o espaço deste tubo com epóxi, para posterior colagem das pastilhas metálicas com o mesmo epóxi. Nesse contexto, o ensaio poderia ser realizado avaliando a resistência de aderência à tração exclusivamente do próprio chapisco na interface com a base. 

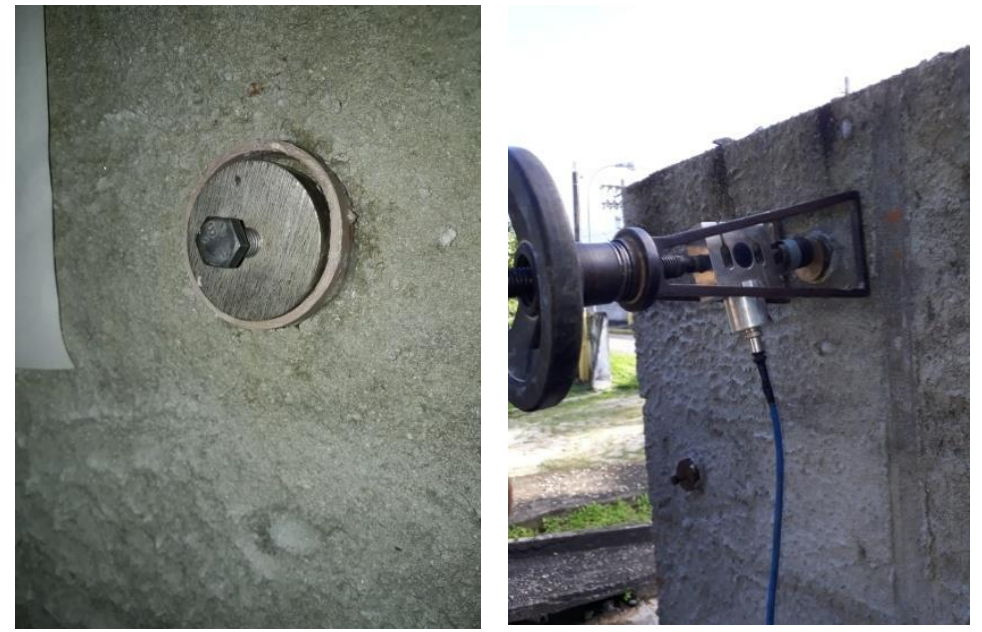

Figura 6: Colagem da peça metálica sobre a superfície da camada de epóxi (preenchimento da cavidade do tudo de PVC) [sobre o chapisco (esquerda)]; posicionamento do aderímetro (direita).

Os dados de saída foram analisados mediante parâmetros estatísticos a partir da análise de variância (ANOVA).

\subsubsection{Ensaios da resistência de aderência à tração de todo sistema de revestimento: "chapisco mais a camada de revestimento de argamassa industrial" aplicado sobre paredes com blocos cerâmicos e paredes com blocos de concreto}

A Figura 7 mostram as paredes construídas no interior do laboratório para ensaios de aderência de todo sistema de revestimentos "chapisco mais revestimento de argamassa industrial (reboco)".

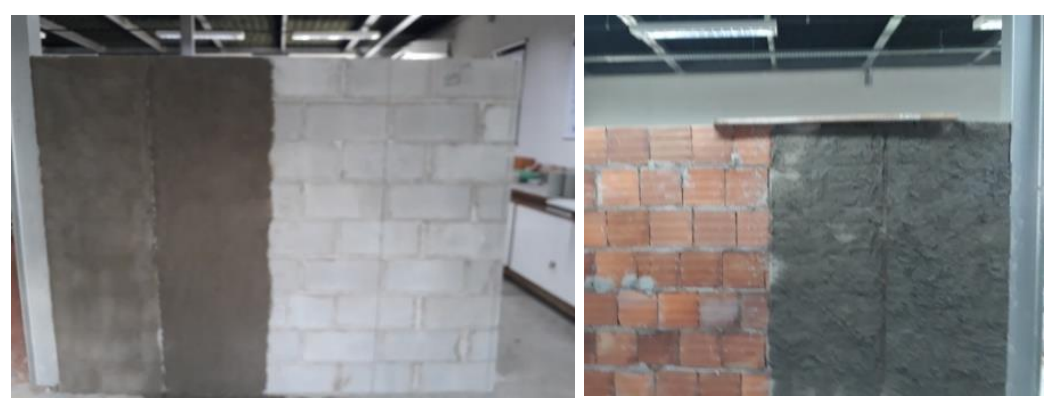

Figura 7: Paredes de vedação sendo chapiscadas: bloco concreto (esquerda) e cerâmico (direita).

Foram aplicados chapiscos com e sem adição de cal nas alvenarias, nas proporções $0 \%, 5 \%, 10 \%$ e $15 \%$ em relação a massa de cimento. Entretanto, para adição de cal somente no revestimento, considerou-se proporcionalmente adição em relação ao cimento diante da informação do fabricante da argamassa industrializada, i.e.: teor de $30 \%$ de cimento em relação a massa total.

A cura foi feita com aspersão controlada de água (cura úmida) durante 3 dias seguidos após aplicação do chapisco com $5 \mathrm{~mm}$ de espessura. Decorrido esse período de cura do chapisco, foi aplicado por meio de projeção manual a argamassa de revestimento industrializada (espessura de $20 \mathrm{~mm}$ ) sobre as duas paredes, utilizando relação água/argamassa de revestimento industrializada estabelecida pelo fabricante e posterior nova cura úmida por 3 dias seguidos. Todas as atividades foram realizadas pelo mesmo oficial pedreiro, com o intuito de evitar distorções nos ensaios (Figura 8).

A Tabela 8 apresenta as tabulações das Famílias estudadas nas duas situações, tendo em vista que se buscou investigar a influência da cal separadamente nas duas camadas do sistema de revestimento (chapisco/reboco).

(i) Adição de cal somente na camada do revestimento reboco (sem adição de cal na camada do chapisco);

(ii) adição de cal somente no chapisco (sem adição de cal na camada do revestimento reboco). 


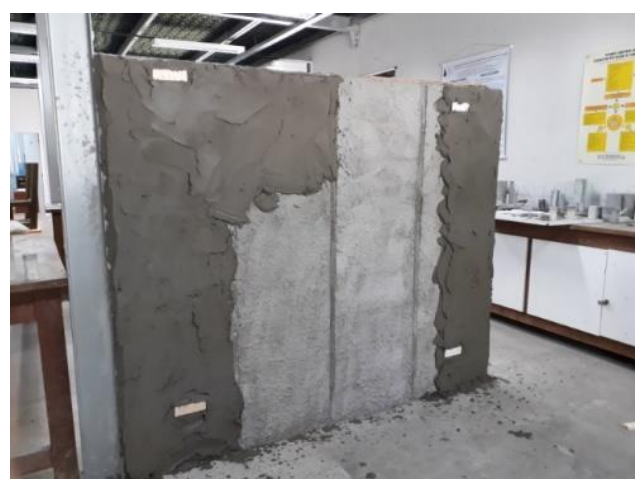

Figura 8: Substrato com argamassa de revestimento sendo aplicado.

Tabela 8: Teores de adição de cal nas famílias estudadas para verificação da "aderência de todo sistema de revestimento" (chapisco mais reboco industrializado).

\begin{tabular}{|c|c|c|c|c|c|c|c|c|c|c|c|c|c|c|}
\hline \multicolumn{15}{|c|}{ FAMÍLIAS DO SISTEMA DE REVESTIMENTO: TEOR DE CAL [“CHAPISCO; REVESTIMENTO” (\%)] } \\
\hline \multirow{2}{*}{ CAMADA } & \multicolumn{14}{|c|}{ SUBSTRATOS } \\
\hline & \multicolumn{7}{|c|}{ BLOCO CERÂMICO } & \multicolumn{7}{|c|}{ BLOCO DE CONCRETO } \\
\hline Chapisco & 0 & $5 \%$ & $10 \%$ & $15 \%$ & 0 & 0 & 0 & 0 & $5 \%$ & $10 \%$ & $15 \%$ & 0 & 0 & 0 \\
\hline Reboco & 0 & 0 & 0 & 0 & $5 \%$ & $10 \%$ & $15 \%$ & 0 & 0 & 0 & 0 & $5 \%$ & $10 \%$ & $15 \%$ \\
\hline
\end{tabular}

Decorridos 28 dias, foram realizados ensaios para determinação da resistência de aderência à tração (18 exemplares por família) seguindo os procedimentos descritos em norma pertinente [1].

Os testes foram efetuados em corpos de prova circulares com $50 \mathrm{~mm}$ de diâmetro, sendo o aderímetro instalado sobre pastilhas metálicas coladas com adesivo epóxi de alta aderência. Antes da colocação destas peças metálicas foram efetuados riscos a partir da face lateral da parede, assegurando que as mesmas fossem posicionadas exclusivamente sobre a superfície dos blocos, e não nas juntas de assentamento. Também se evitou a aproximação entre os pontos de ensaio para não haver interferência desfavorável devido a possíveis fragilidades na região, por conta dos cortes com a serra copo.

Os dados foram analisados mediante parâmetros estatísticos com análise de variância (ANOVA), em nível de significância de 95\%, que realiza comparação de dois grupos independentes, para verificar se pertence ou não à mesma população.

\section{RESULTADOS E DISCUSÕES}

As discussões serão apresentadas separadamente, conforme as duas condições estudadas:

1) Verificação da resistência de aderência à tração exclusiva do "chapisco"/substrato cerâmico;

2) Resistência de aderência à tração de todo sistema de revestimento incluindo o "chapisco mais a camada de argamassa industrializada"/substratos (cerâmico e concreto).

\subsection{Resistência de aderência à tração exclusivamente na interface "chapisco"/alvenaria com blocos cerâmico}

Os resultados dos ensaios estão apresentados na figura 9, indicando os valores médios e os respectivos coeficientes de variação obtidos nas 12 réplicas ensaiadas para cada família estudada. 


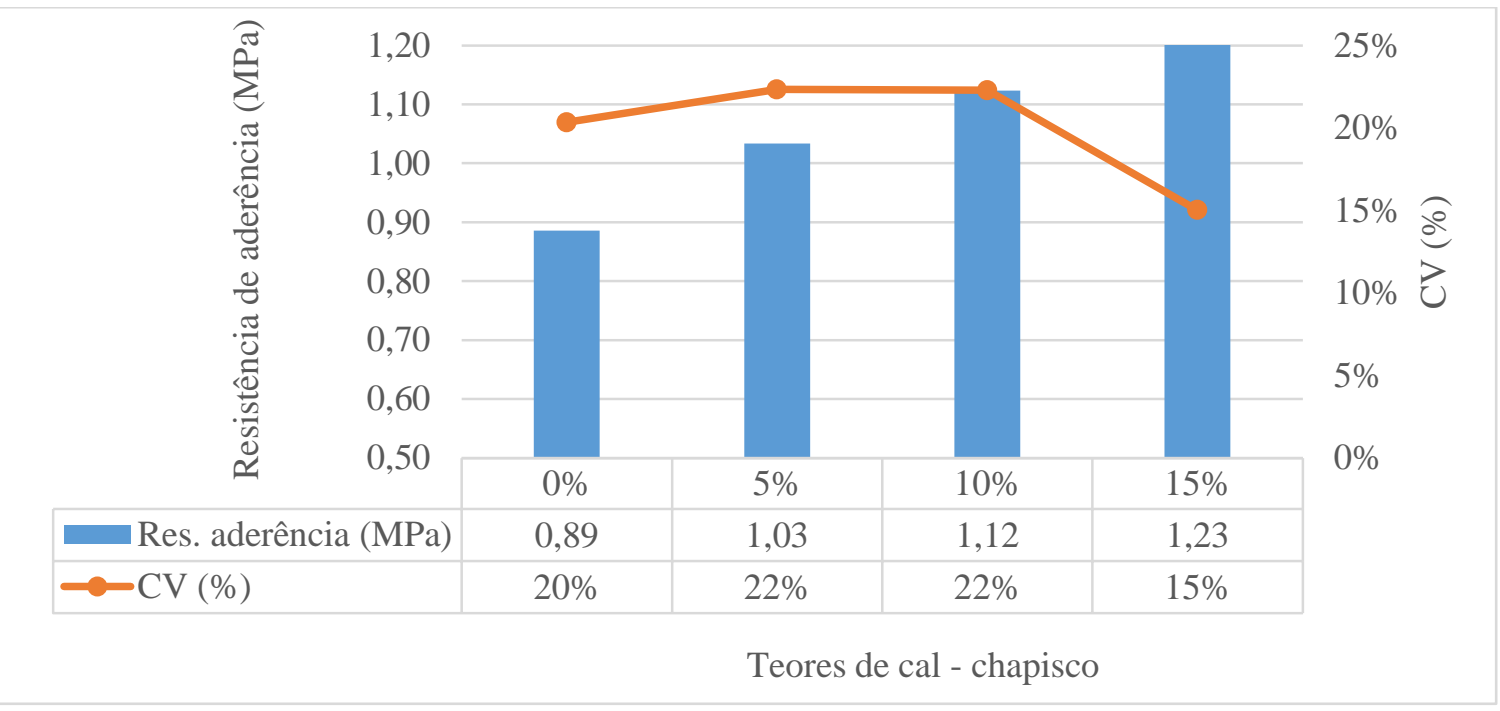

Figura 9: Resistência de aderência à tração (interface).

A partir desses dados verifica-se uma tendência de incremento na aderência entre o chapisco e a base com o aumento no teor de cal no chapisco, com ganhos potenciais de $16 \%, 26 \%$ e $39 \%$ em relação à referência com o chapisco convencional, sem o emprego da cal.

Esses resultados corroboram com a melhoria da extensão de aderência de argamassa cimentícia na interface com substratos, também confirmado pela análise de variância (Tabela 9).

Os valores elevados da resistência de aderência à tração, podem ser justificados diante de duas possibilidades prováveis, ou sejam: (1) o ensaio ocorreu de forma direta, sem que houvesse qualquer dano/fragilidade ao corpo de prova devido corte da argamassa com broca serra copo para colagem do aparato metálico para arrancamento, conforme preconiza a norma pertinente; (2) ao colar uma medida de tubo com silicone sobre a camada de chapisco para preenchimento dessa cavidade com massa epóxi, objetivando a colagem do aparato metálico para arrancamento, é possível que a região tangencial a este corpo de prova do chapisco em ensaio, contribua na coesividade somando uma certa parcela na tensão resistente. Neste caso, pode-se refletir que é uma condição natural no contexto da aderência argamassa/base, e, por conseguinte, melhor representa a realidade.

Tabela 9: Anova com nível de significância de 95\% (teores de cal no chapisco).

\begin{tabular}{c|c|c|c}
\hline INFLUÊNCIA & $F_{\text {CALCULADO }}$ & $F_{\text {CRíTICO }}$ & DIFERENÇA SIGNIFICATIVA \\
\hline Referência $(0 \%) \times 5 \%$ & 3,06 & 4,3 & Não \\
\hline Referência $(0 \%) \times 10 \%$ & 7,10 & 4,3 & SIM \\
\hline Referência (0\%) x 15\% & 21,3 & 4,3 & SIM \\
\hline
\end{tabular}

Vale salientar que, os resultados se aplicam as variáveis dessa pesquisa, o que denota a importância de novos estudos mais aprofundados para verificação do potencial de ganho encontrado a partir do uso desse tipo de técnica.

3.2 Resistência de aderência à tração de todo sistema de revestimento "chapisco mais a camada de argamassa industrializada" aplicado em alvenarias de blocos cerâmico e de concreto

Variando as adições de cal $(0 \%, 5 \%, 10 \%, 15 \%)$, adicionou-se cal somente na "camada da argamassa de revestimento industrializada (reboco)" e posterior somente no "chapisco" (conforme especificado na Tabela 8). Buscou-se verificar a aderência de todo sistema de revestimento, considerando na análise dos resultados não somente a tensão calculada, mas também a forma de ruptura.

3.2.1 Situação 1: influência da adição de cal somente na argamassa de revestimento industrializada (sem adição de cal no chapisco)

Os resultados obtidos estão apresentados na Figura 10, que indicam o valor médio encontrado em 18 amostras ensaiadas para cada família estudada. 


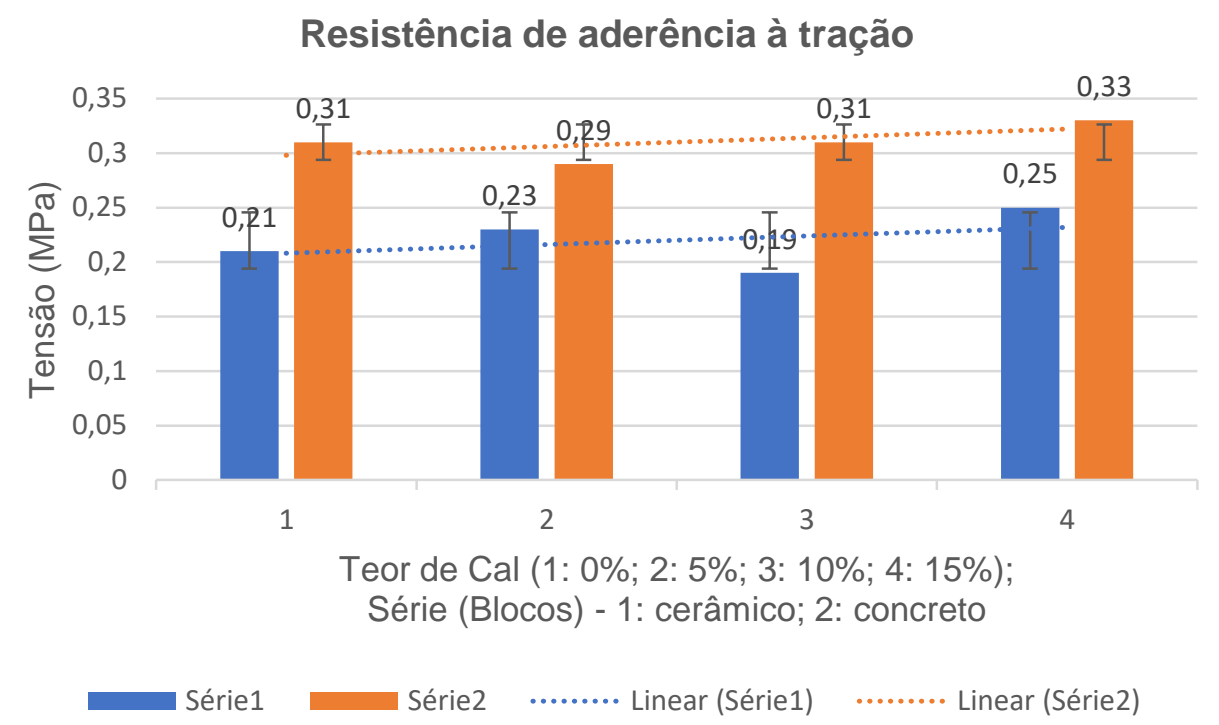

Figura 10: Resistência de aderência à tração devido a adição de cal no revestimento industrializado, com as linhas de tendência linear e desvio padrão.

Verifica-se que, a contribuição da cal na argamassa de emboço não se mostrou expressiva, o que pôde ser comprovado a partir da análise de variância (ANOVA) realizada com intervalo de confiança de 95\%, onde não foi observada diferença significativa entre as amostras (Tabela 10).

Tabela 10: Análise de variância (influência da cal no emboço), nível de significância de $95 \%$.

\begin{tabular}{l|l|l|l}
\hline INFLUÊNCIA & FALCULADo $_{\text {CRÍtICo }}$ & DIFERENÇA SIGNIFICATIVA \\
\hline BLOCO DE CONCRETO & & & \\
\hline Referência (0\%) x 5\% & 0,13 & 4,13 & Não \\
\hline Referência (0\%) x 10\% & 0,005 & 4,13 & Não \\
\hline Referência (0\%) x 15\% & 0,3 & 4,13 & Não \\
\hline TIJOLO CERÂMICO & & & \\
\hline Referência (0\%) x 5\% & 1,25 & 4,13 & Não \\
\hline Referência (0\%) x 10\% & 0,44 & 4,13 & Não \\
\hline Referência (0\%) x 15\% & 3,82 & 4,13 & Não \\
\hline
\end{tabular}

É importante destacar que nesses casos, a ruptura predominante foi do tipo coesiva ( $85 \%$ fora da interface base/revestimento), em sua maioria no corpo da própria argamassa de emboço, o que dificulta uma análise mais efetiva da eventual contribuição, e.g.: na aderência na interface entre as camadas. Portanto, pode-se inferir que, diante de rupturas em proporção significativa no corpo da camada de revestimento industrializada, não se pôde atestar o efeito favorável da adição da cal na aderência neste sistema.

3.2.2 Situação 2: influência da adição de cal exclusivamente no chapisco (sem adição de cal na argamassa de revestimento industrializada)

Os valores encontrados estão apresentados na Figura 11, obtidos a partir da média de 18 amostras ensaiadas para cada Família. 


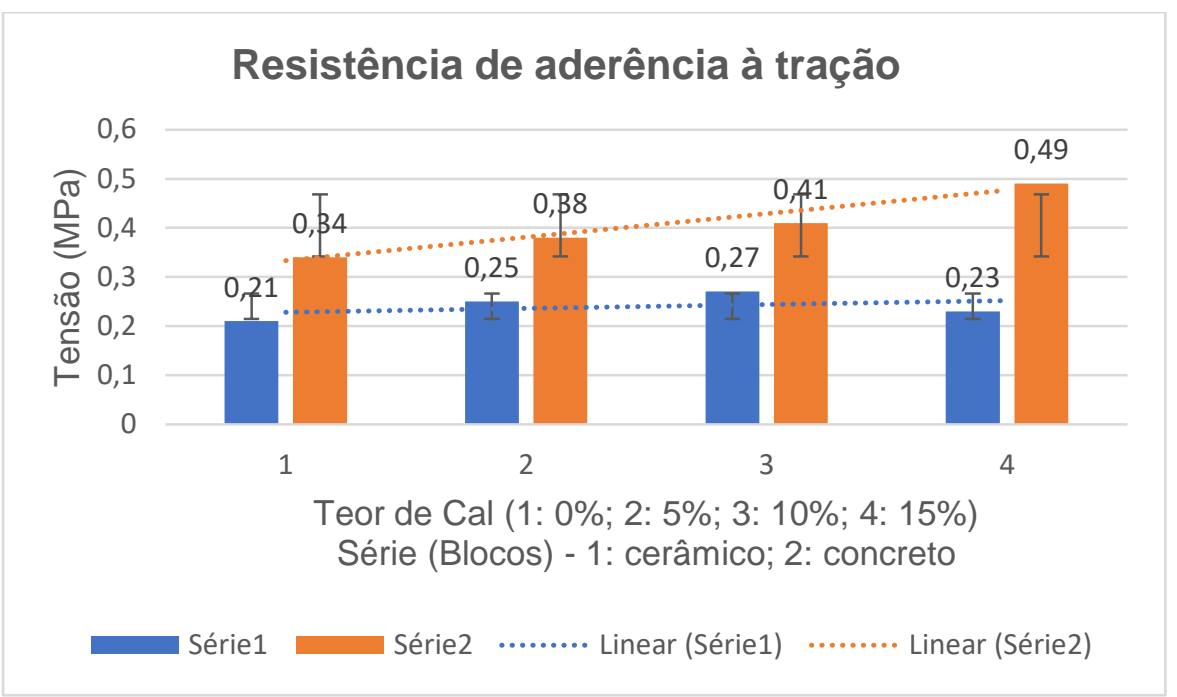

Figura 11: Resistência de aderência à tração devido a adição de cal somente no chapisco.

Neste caso, foi identificada influência importante da cal na aderência, especialmente para os teores de $15 \%$, para blocos de concreto, e de $10 \%$ para os blocos cerâmicos (Tabela 11).

Em comparação com a amostra de referência ( $0 \%$ de cal), nos teores de adição com 5\%, 10\%, 15\% foram percebidos ganhos potenciais respectivos de $12 \%, 21 \%$, e, $44 \%$ para o teor de $15 \%$ de cal na mistura, isto para os blocos de concreto. Por sua vez, em substrato cerâmico verificaram-se incrementos de 19\%, 29\% e $10 \%$ quando comparado com amostra de referência.

Esses resultados apontam para uma influência marcante em substrato com blocos de concreto, o que pode ser decorrente da sua natural maior rugosidade e sucção inicial, características que torna a base mais sensível às superfície de contato com a argamassa (interface), ocasionado pela microancoragem decorrente do travamento mecânico dos cristais produzidos na hidratação do cimento (C-S-H e, fundamentalmente, etringita) nos poros da parede (princípio dos poros ativos).

Tabela 11: ANOVA com nível de significância de 95\% (influência da cal no chapisco).

\begin{tabular}{l|l|l|l}
\hline INFLUÊNCIA & FCALCULADO & F $_{\text {CRÍTICO }}$ & DIFERENÇA SIGNIFICATIVA \\
\hline BLOCO DE CONCRETO & & & \\
\hline Referência (0\%) x 5\% & 0,86 & 4,13 & Não \\
\hline Referência (0\%) x 10\% & 2,9 & 4,13 & Não \\
\hline Referência (0\%) x 15\% & 11,1 & 4,13 & SIM \\
\hline TIJOLO CERÂMICO & & & \\
\hline Referência (0\%) x 5\% & 3,21 & 4,13 & Não \\
\hline Referência (0\%) x 10\% & 6,8 & 4,13 & SIM \\
\hline Referência (0\%) x 15\% & 0,94 & 4,13 & Não \\
\hline
\end{tabular}

Interessante notar ainda uma leve queda nos valores alcançados na família de estudos com 15\% de cal para o caso dos tijolos cerâmicos, o que pode indicar um teor ótimo potencial para esse tipo de aplicação para esse tipo de base $10 \%$.

A forma de ruptura predominante observada foi aproximadamente $85 \%$ no interior da camada de revestimento (ruptura coesiva).

Os resultados obtidos nas duas situações, além de indicar a maior importância de adição de cal na camada de chapisco, também apontou maiores aderências em alvenaria com bloco de concreto quando comparados com tijolo cerâmico. Esta constatação pode ser justificada considerando que a superfície mais lisa e densa deste elemento, proporciona maiores dificuldades para a microancoragem e macroancoragem.

Importante condicionante acerca da forma operacional do ensaio foi observado, uma vez que o corte circular com o equipamento furadeira e broca de vídea tipo serra copo, demanda que o operador seja por de- 
mais treinado e capacitado, na medida em que quaisquer inclinações, por mais tênue que seja, quebra a ortogonalidade que deve ser perfeita entre o eixo do equipamento com o plano da parede. Em assim sendo, serão impostas fragilidades na região do corpo de prova devido acréscimos de tensões de torção, mitigando a rigidez e integralidade dos corpos de prova ensaiados $[14,36]$.

\section{CONCLUSÕES}

Com base nos resultados obtidos, podem-se apresentar algumas considerações importantes acerca da influência da cal na resistência de aderência à tração nas condições estudadas:

1) Amostras com "chapisco" aplicado sobre alvenaria com blocos cerâmicos de vedação:

Houve incremento na resistência de aderência à tração devido adição de cal. Foi identificada influência significativa, com nível de confiança de $95 \%$, para os teores de $10 \%$ e $15 \%$ de cal em relação às amostras de referência, com ganhos de até $39 \%$ na aderência. Nesse caso, destaca-se ainda a adequação do método de ensaio adaptado [1], para avaliação exclusiva da aderência do chapisco à base, percebido a partir da forma de ruptura observada no bloco $(85 \%)$ e na interface do chapisco/base $(15 \%)$.

2) Amostras com todo sistema de revestimento "chapisco mais revestimento de argamassa industrializada":

2.1) As Famílias em que o experimento foi realizado com adição de cal somente na argamassa de revestimento (sem adição na camada de chapisco), não se identificou influência na resistência de aderência à tração para quaisquer dos teores empregado, tanto para as bases com blocos de concreto quanto para blocos cerâmicos. A forma de ruptura, em geral, foi ao longo do corpo de prova do revestimento (tipo coesiva: próximo de $85 \%)$.

2.2) Quanto a adição de cal somente na camada do chapisco, com posterior aplicação da argamassa de revestimento industrializada (sem adição de cal), verificou-se satisfatória influência na resistência de aderência à tração (com nível de confiança de 95\%, pela análise de variância) para os teores de $15 \%$ no caso de blocos de concreto, e de $10 \%$ para os tijolos cerâmicos, com ganhos de $44 \%$ e $29 \%$ respectivamente, em comparação com as amostras de referência. Sendo a forma de ruptura observada em sua maioria no corpo da argamassa de revestimento (ruptura coesiva), 85\% aproximadamente. Neste caso, a real resistência da aderência na interface poderia ser igual ou superior. Percebe-se, por conseguinte, que é preciso agir fortemente não apenas na acurácia das ligações da interface (base/revestimento), mas sobretudo na capacidade de suporte de todo o sistema de revestimento.

Os maiores valores de aderência quando adicionou-se cal somente no chapisco, foram obtidos em bases com bloco de concreto em comparação com cerâmicos, provavelmente pelo maior travamento mecânico (base/chapisco) devido melhor absorção inicial da água coloidal presente na pasta pelos poros do substrato, tendo em vista incrementando na rede de povoamento dos cristais de etringita e C-S-H (microancoragem - princípios dos poros ativos). Somando-se a consideração anterior, é possível creditar a maior rugosidade superficial dos blocos de concreto, o favorecimento à macroancoragem, sendo este um fato importante por contribuir com a resistência ao cisalhamento, principalmente nos casos de fachadas.

Destaca-se que, a solução proposta é de fácil implementação em canteiro de obras, dada a natural disponibilidade de cal e a simples alteração no procedimento de preparação das argamassas. Adicionalmente, percebe-se também benefícios diversos com adição de cal nas argamassas, à saber: melhor comportamento reológico (consistência/trabalhabilidade); retenção adequada de água; extensão de aderência; deformabilidade etc.

Por fim, para a continuidade da pesquisa, pode-se sugerir algumas opções de experimentos: (a) avaliar a aplicação do chapisco e sistema de chapisco mais emboço - diretamente em base de concreto estrutural; (b) acrescentar outros teores de adição de cal, incluindo adições minerais (pozolanas), para avaliar outros possíveis benefícios na aderência; (c) utilizar aparato como trava, de modo que o corte ocorra até a região da interface chapisco/revestimento, objetivando verificar a tensão de aderência nesta região; (d) reprisar todos os ensaios sugeridos, mudando de corte circular para retangular (com disco de corte), objetivando compilar os métodos e identificar maior acurácia da aderência à tração devido mitigação das fragilidades operacionais do ensaio normalizado.

\section{AGRADECIMENTOS}

Ao Instituto Federal de Ciência e Tecnologia de Pernambuco IFPE/Campus Recife e a empresa TECOMAT Engenharia pela colaboração com os ensaios dessa pesquisa. 


\section{BIBLIOGRAFIA}

[1] ASSOCIAÇÃO BRASILEIRA DE NORMAS TÉCNICAS. NBR 13528: revestimentos de paredes e tetos de argamassas inorgânicas: determinação da resistência de aderência. Rio de Janeiro, 2010.

[2] COSTA e SILVA, A.J. Descolamento dos revestimentos cerâmicos de fachada na cidade do Recife. São Paulo, 2001. Dissertação (Mestrado em Engenharia Civil), Universidade de São Paulo, São Paulo, 2001.

[3] MOTA J.M.F. Influência da argamassa de revestimento na resistência à compressão axial em prismas de alvenaria resistente de blocos cerâmicos. Recife, 2006. Dissertação (Mestrado em Engenharia Civil), Universidade Federal de Pernambuco, Recife, 2006.

[4] MOTA, J.M.F., OLIVEIRA, R.A., CARNEIRO, A.M.P. "Durabilidade de argamassas com adição de metacaulim para reforço de alvenaria”. Revista Matéria v.21 n.4, pp. 1105-1116. 2016.

[5] MOTA, J.M.F. Reforço de alvenarias resistente com argamassa armada e adição de metacaulim. Recife, 2015. Tese (Doutorado em Engenharia Civil), Universidade Federal de Pernambuco, Recife, 2015.

[6] SILVA, V. Aderência de chapiscos em concretos estruturais - melhoria da microestrutura da zona de interface pela adição da sílica da casca de arroz. São Carlos, 2004. Tese (Doutorado em Engenharia Civil) Universidade de São Paulo, São Paulo, 2004.

[7] RUDUIT, F.R. Contribuição ao estudo da aderência de revestimento de argamassa e chapiscos em substrato de concreto. Porto Alegre, 2009. Dissertação (Mestrado em Engenharia Civil) - Programa de PósGraduação em Engenharia Civil, Universidade Federal do Rio Grande do Sul, Porto Alegre, 2009.

[8] CARASEK, H. Guia de avaliação e interpretação de ensaios de sistemas de revestimentos de argamassa. Comunidade da Construção de Belo Horizonte. 21 p. $4^{\circ}$ Ciclo. Belo Horizonte, 2011.

[9] PAES, I.N.L. Avaliação do transporte de água em revestimentos de argamassa nos momentos iniciais pós-aplicação. Brasília, 2004. Tese (Doutorado em Engenharia Civil) - Universidade de Brasília, Brasília-DF, 2004.

[10] ZANELATO, E.B. Influência do chapisco na resistência de aderência à tração de revestimentos de argamassa em blocos cerâmicos. Campos dos Goytacazes, 2015. Dissertação (Mestrado em Engenharia Civil). Universidade Estadual do Norte Fluminense Darcy Ribeiro, Campos dos Goytacazes, 2015.

[11] CARASEK, H. Aderência de argamassa à base de cimento Portland a substratos porosos - avaliação dos fatores intervenientes e contribuição ao estudo do mecanismo da ligação. São Paulo, 1996. Tese (Doutorado em Engenharia Civil), Universidade de São Paulo, São Paulo, 1996.

[12] TORRES, I., VEIGA, M.R., FREITAS, V.P. "Influence of substrate characteristics on behavior of applied mortar". Journal of Materials in Civil Engineering. v.30. Issue10. Oct 18. 2018.

[13] CARASEK, H. "Fatores que exercem influência na resistência de aderência de argamassas". In: II SIMPÓSIO BRASILEIRO DE TECNOLOGIA DE ARGAMASSAS. Salvador, 1997. Anais... SBTA, Salvador, 1997.

[14] APOLÔNIO, P.H., MOTA, J.M.F., BARBOSA, F., et al. "Análise comparativa da resistência de aderência do chapisco com diferentes relações água/ligante e adição de metacaulim". In: SIMPÓSIO BRASILEIRO DE TECNOLOGIA DAS ARGAMASSAS, XI, Porto Alegre, 2015. Anais... Porto Alegre, UFRGS, ANTAC, 2015.

[15] CARASEK, H., CASCUDO, O., SCARTEZINI, L.M. "Importância dos materiais na aderência dos revestimentos de argamassas". In: SIMPÓSIO BRASILEIRO DE TECNOLOGIA DAS ARGAMASSAS, IV, Brasília, 2001. Anais... Brasília, UnB, ANTAC, 2001.

[16] BOTAS, S., ROSÁRIO, M., VELOSA, A. "Air lime mortars for conservation of historic tiles: Bond strength of new mortars to old tiles". Construction and Building Materials v.145, pp. 426-434. 2017.

[17] STOLZ, C.M., MASUERO, A.B., PAGNUSSAT, D.T., et al., "Influence of substrate texture on the tensile and shear bond strength of rendering mortars". Construction and Building Materials v.128, pp. 298307. 2016.

[18] AZEVEDO, A.R.G., FRANÇA, B.R., ALEXANDRE, J., et al., "Influence of sintering temperature of a ceramic substrate in mortar adhesionfor civil construction. Journal of Building Engineering" v.19. pp.342348. 2018.

[19] DETRICHÉ, C.H., GALLIAS, J.L., GRANDET, J., et al., Influence des paramétres de mise en ouvre et de composition sur le comportament des mortiers d'enduit. Matériaux et constructions, 1985.

[20] DUPIN, I., DÉTRICHÉ, C.H., MASO, J.C. "Accrochage direct d'un enduit sur un isolant par une liaison de type mécanique dans le cadre d'un procédé d'isolation par I'esterieur". Matériaux et constructions, 1988.

[21] WINSLOW, D., LIU, D. The pore structure of paste in concert. Cement and Concrete Research, 1990. 
[22] BECKER, F.A., ANDRADE, J.J.O. "Avaliação da influência do substrato de concreto na resistência de aderência à tração de diferentes tipos de chapisco". Revista Matéria v.22 n.04, e-11906. 2017.

[23] HERRMANN, T.D., MOHAMAD, G., LIMA, R.C.A., et al., "Estudo de caso do desempenho de estanqueidade à água de argamassas e hidrorrepelentes" - Parte I. Revista Matéria v.24 n.04, e-12516, 2019.

[24] SANTOS, A.M., COSTA e SILVA, A.J., MOTA, J.M.F. "Influência da cal na aderência da cal para revestimento". In: SIMPÓSIO BRASILEIRO DE TECNOLOGIA DAS ARGAMASSAS, XIII, Goiânia, 2019. Anais... Goiânia, UFG, ANTAC, 2019.

[25] THOMAZ, E. Tecnologia, gerenciamento e qualidade na construção. São Paulo: Editora Pini. 2001.

[26] YAZIGI, W.A Técnica de edificar, $6^{a}$ Ed., São Paulo: Editora Pini, 2004.

[27] MOURA, C.B. Aderência de revestimentos externos de argamassa em substratos de concreto: influência das condiçães de temperatura e ventilação a cura do chapisco. Porto Alegre, 2007. Dissertação (Mestrado em Engenharia Civil) - Universidade Federal do Rio Grande do Sul, Porto Alegre, 2007.

[28] VOSS, W.C. Permeability of brick masonry walls: an Hypothesis American Society forTesting Materials. Proceedings. Philadelphia, 1933.

[29] CHASE, G.W. "The effect of pretreatments of clay brick on brick-mortar bond strength". In: North American Masonry Conference, 3rd., Arlington, June 1985.

[30] SCARTEZINI, L.M., CARASEK, H. "Fatores que exercem influência na resistência de aderência à tração dos revestimentos de argamassas". In: SIMPÓSIO BRASILEIRO DE TECNOLOGIA DAS ARGAMASSAS, V, São Paulo, 2003. Anais... São Paulo, EPUSP, ANTAC, 2003.

[31] MOTA, J.M.F., COSTA e SILVA, A.J., CARASEK, H., et al., "Análise em obra da resistência de aderência de revestimentos de argamassa com o preparo do substrato com solução de cal e chapisco". In: X CONGRESO LATINOAMERICANO DE PATOLOGÍA Y XII CONGRESO DE CALIDAD EN LA CONSTRUCCIÓN. CONPAT 2009. Anais... Valparaíso-Chile, 2009.

[32] COSTA e SILVA, A.J., AZEVEDO, A.A.C.; SOUZA, M.T.G. "Influência da preparação da base na aderência de revestimentos de argamassa sobre tijolos cerâmicos". 7th EURO-AMERICAN CONGRESS ON CONSTRUCTION PATHOLOGY, REHABILITATION TECHNOLOGY AND HERITAGE MANAGEMENT - Rehabend 2018. Cáceres, Spain, 2018.

[33] ANGELIM, R.R. "Eficiência do preparo de substrato de blocos cerâmicos com solução de cal na resistência de aderência dos revestimentos de argamassa". In: VI SIMPÓSIO BRASILEIRO DE TECNOLOGIA DE ARGAMASSA, VI, Florianópolis, 2005. Anais... Florianópolis: UFSC, ANTAC, 2005.

[34] CUNHA, S., AGUIAR, J., FERREIRA, V., et al., "Argamassas com incorporação de materiais de mudança de fase (PCM): Caracterização física, mecânica e durabilidade". Revista Matéria v.20, n.01, pp. 245261. 2015.

[35] MOTA, J.M.F., CARASEK, H., COSTA e SILVA, A.J, et al., "Argamassas inorgânicas com adição de metacaulim”. In: SIMPÓSIO BRASILEIRO DE TECNOLOGIA DAS ARGAMASSAS, IX, Belo Horizonte, 2011. Anais... Belo Horizonte, UFMG, ANTAC, 2011.

[36] MARANHÃO, F.L. Palestra ministrada em 16/08/2019 no evento CONCRETESHOW: Patologias em revestimento com ladrilho hidráulico. São Paulo, 2019.

\section{ORCID}

André Miranda dos Santos Ângelo Just da Costa e Silva João Manoel de Freitas Mota https://orcid.org/0000-0003-3055-8411

https://orcid.org/0000-0002-0759-6439

https://orcid.org/0000-0001-7961-5494 